and oxygenation may be obtained with PTV and HFJV, we have. some reservations about this technique in these patients. Access to the neck is often obstructed by various devices serving to stabilize the neck, rendering the placement of the transtracheal catheter problematic. These patients are often moved in the process of evaluation, as from stretcher to CT table, jeopardizing what may be already a tenuous airway. Finally, there is little evidence that the airway is adequately protected from soiling or aspiration in a patient population that is at significant risk for this event. Yealy cites two animal experimental models that suggest the risk of aspiration during PTV is low. However, in Yealy's own work, 66 per cent of dogs, at $45^{\circ}$ of elevation, being ventilated with PTV and HFJV, suffered some degree of aspiration. There was no evidence of aspiration in animals intubated with a cuffed tracheal tube, under the same conditions. In the above situation, we are of the opinion that the priority is a secure and protected airway and that PTV with HFJV may be employed to ensure adequate ventilation and oxygenation while a plan is being formulated to secure the airway with a cuffed tube.

Airway management of patients with known or suspected cervical spinal injury or instability should be dictated by common sense and care and not by a dogmatic approach and reliance on any particular algorithm. This statement is supported by both the critical care literature and the accumulated clinical experience in the management of these patients, in many centres, with a variety of techniques.

E. Crosby MD FRCPC

A. Lui MD FRCPC

Ottawa Civic Hospital

University of Ottawa

\section{Fatal embolism}

To the Editor:

In his editorial, "Fatal Embolism," Dr. Matthews correctly indicates the need for "compulsory national reporting of (anaesthetic-related) mortality and serious morbidity." He suggests that this may be a role for the Department of Health and Welfare.

An alternative source of reporting of mortality, at least, are the provincial coroners and medical examiners. As they already review deaths, it would be logical to have them report to a central office. At the Annual Meeting of Chief Coroners and Medical Examiners (September, 1989, in Quebec City), we presented a systematic method for the investigation of anaesthetic-related deaths. Using such a common data base, information could be collected and collated. We suggested that, at a minimum, all intraoperative deaths become "notifiable," i.e., require mandatory reporting to the coroner/medical examiner. Better still would be a common period of 10-15 days postoperatively for notification of a death. However, the coroners and medical examiners operate under provin- cial law, with twelve different acts, Currently, only three of the provinces/territories (Alberta, Manitoba, Prince Edward Island) require (by law) notification of operative deaths. Amendment of these acts to provide common times and conditions for reporting would be a major step towards helping us to know how many people die in Canada each year because of anaesthetic-related mishaps, the causes of these, and possible preventable factors.

\author{
J.M. Davies, MSc MD FRCPC \\ J.N. Armstrong MD \\ Department of Anaesthesia \\ Foothills Hospital at the University of Calgary \\ REFERENCE \\ 1 Matthews RL. Fatal air embolism. Can J Anaesth 1990; \\ 37: 12-4.
}

\section{Prevention of obstruction of epidural catheter by blood clot}

To the Editor:

I read with interest the case report described by Cohen and Amar. ${ }^{1}$ In the described case it was possible to dislodge a blood clot by reinserting a new stylet wire through the epidural catheter. A simple measure is described which can prevent blood clot formation when an epidural catheter enters a blood vessel and is positive for blood on aspiration. A $10-\mathrm{ml}$ syringe filled with saline is attached to the epidural catheter and is flushed while the catheter is partially withdrawn. This process is repeated until blood aspiration test is negative. This simple measure of flush and partial withdrawal helps the epidural catheter to come out of the vessel. We have not encountered accidental intravenous injection of local anaesthetic and very rarely need to resite the catheter in patients when an epidural vessel has been punctured.

Chandra M. Kumar FFARCS

Department of Anaesthesia

South Cleveland Hospital

Middlesbrough

Cleveland TS4 3BW

\section{REFERENCES}

I Cohen S, Amar D. A simple solution to blood clot obstruction of epidural catheter during labour. Can J Anaesth 1990; 37: 143-4. 
2 Verniquet $A J W$. Vessel puncture with epidural catheters. Experience in obstetric patients. Anaesthesia 1988; 43 : 154-5.

\section{$R E P L Y$}

$D r$. Kumar reports a valid method of repositioning an epidural catheter that has entered an epidural vessel. We apply this technique in our practice. We agree with Dr. Kunar on the need to prevent blood clot formation. However, in our case report, a clot formed in the catheter while we were preparing the flush synringe with sterile normal saline. In the event that a clot forms, the catheter may still be salvaged by dislodging the blood clot with reinsertion of the stylet wire.

Shaul Cohen MD

David Amar MD

Department of Anesthesiology

Albert Einstein College of Medicine

I 300 Morris Park Avenue

Bronx, NY 10461

\section{Epidural morphine injections for the treatment of postspinal headache}

To the Editor:

Postspinal headache (PSH) was first documented by August Bier.' In 1898, he reported severe headache following subarchnoid injection of cocaine which was exacerbated by sitting or standing, and relieved by lying down. The incidence of PSH varies between 0.4 per cent $^{2}$ and 70 per cent. ${ }^{3}$ The most accepted theory of PSH relates it to CSF hypovolaemia, produced by escape of CSF through the dural vent, which deprives the brain of its cushion and places tension on its pain-innervated anchoring structures. ${ }^{4}$

Tourtellotte et al.$^{5}$ listed 49 modalities of treatment for PSH, ranging, alphabetically, from an abdominal binder to irradiation of the skull. Even surgical repair of the dural hole was advocated in persistent cases. ${ }^{6}$

Currently, the most accepted mode of therapy for PSH was introduced by Gormley; ${ }^{7}$ autologous blood is introduced into the epidural space in the vicinity of the presumed dural hole, resulting in effective and total relief of headache. However, failure of this mode of therapy was reported recently. 8,9

We report six patients (28-70 yr old) with PSH in whom total relief of pain was obtained by epidural injections of morphine via an epidural catheter. Five of the patients developed PSH after surgery using combined spinal-epidural anaesthesia. The spinal injections were done through a 25 -gauge needle. An epidural catheter was left in place for supplemental anaesthesia or postoperative analgesia. Epidural morphine $3.5-4.5 \mathrm{mg}$ was injected postoperatively. On the first postoperative day the patients developed PSH. Another injection of epidural morphine, $3.5-4.5 \mathrm{mg}$, relieved the pain after $30 \mathrm{~min}$, and the pain did not return. The sixth patient, $28 \mathrm{yr}$ old, underwent an inadvertant dural puncture with a 19G needle used for the introduction of the 25G spinal needle. Thirty-six hours later she developed PSH. An epidural catheter was introduced into the $\mathrm{L}_{2-3}$ interspace, and morphine $3.5 \mathrm{mg}$ was injected through it. After $45 \mathrm{~min}$ her headache was relieved. Twenty hours later she complained again of PSH. Another injection of morphine 3.5 $\mathrm{mg}$ through the epidural catheter resulted in disappearance of the headache after $45 \mathrm{~min}$, without its return.

There have been several reports of the successful use of epidural morphine after inadverdent spinal tap to prevent post-spinal headache, ${ }^{10.11}$ but this, to our knowledge, is the first report of the beneficial use of this modality after headaches have occurred. The availability of this technique may detract from the reservations of using spinal anaesthesia in young adults. Our experience also challenges the CSF leakage theory of PSH.

Joseph Eldor MD

Pierre Guedj MD

Shamay Cotev MD

Department of Anaesthesia

Hadassah University Medical Center, Ein Karem

P.O. Box 12000

Jerusalem 91120

Israel

\section{REFERENCES}

1 Bier $A$. Experiments regarding the cocainization of the spinal cord. Zeitschrift fur Chisurgie 51: 36I-369. April 1899 (Translated and reprinted in "Classical File", Survey of Anesthesiology 1962: 6: 352-8).

2 Greene BA. Twenty-six gauge lumbar puncture needle: its value in the prophylaxis of headache following spinal analgesia for vaginal delivery. Anesthesiology 1950; 11 : 464-9.

3 Crawford JS. Experience with epidural blood patch. Anaesthesia 1980; 35: 513-5.

4 Digiovanni AJ, Galbert MW, Wahle WM. Epidural injection of antologous blood for postlumbar-puncture headache. Anesth Analg Curr Research 1972; 51: 226-232.

5 Tourtellotie WW, Haerer AF, Heller GG et al. Post Lumbar Puncture Headaches. Springfield, lllinois, Charles C. Thomas, Publisher, 1964. 